\title{
Upaya Meningkatkan Hasil Belajar Bahasa Inggris Aspek Reading Skill Ability Melalui Pronounciation Word By Word di SD Muhammadiyah 2 Parepare
}

\author{
Hadiwaratama R Jusran \\ SD Muhammadiyah 2 Parepare, Kota Parepare - Provinsi Sulawesi Selatan \\ *Corresponding Author. Email: hadiwr84@gmail.com
}

\begin{abstract}
This study aims to improve learning outcomes in English aspects of reading skill ability through the word by word pronunciation learning method. This classroom action research was conducted in two cycles. The subjects of this study were fourth grade students of SD Muhammadiyah 2 Parepare with a total of 10 people. The data collection technique of this research used observation, tests, and field notes. While the data analysis technique used descriptive analysis. The results of this study indicate that the increase in learning for fourth grade students of SD Muhammadiyah 2 Parepare through pronunciation word by word is in the first cycle in the low category with an average score of 53.00, while in the second cycle there is an increase in the high category with an average value. average 85.00. In connection with these results, it can be concluded that the learning method of pronounciation word by word can improve learning outcomes of English aspects of reading skill ability for fourth grade students of SD Muhammadiyah 2 Parepare.
\end{abstract}

\begin{abstract}
Abstrak: Penelitian ini bertujuan untuk meningkatkan hasil belajar bahasa inggris aspek reading skill ability melalui metode pembelajaran pronounciation word by word. Penelitian tindakan kelas ini dilakukan dalam dua siklus. Subjek penelitian ini adalah siswa kelas IV SD Muhammadiyah 2 Parepare dengan jumlah sebanyak 10 0rang. Teknik pengumpulan data penelitian ini menggunakan observasi, tes, dan catatan lapangan. Sedangkan teknik analisis datanya menggunakan analisis deskriptif. Hasil penelitian ini menunjukkan bahwa peningkatan belajar siswa kelas IV SD Muhammadiyah 2 Parepare melalui Pronounciation word by word adalah pada siklus I masuk dalam kategori rendah dengan jumlah nilai rata-rata 53,00, sedangkan pada siklus II mengalami peningkatan dengan kategori tinggi dengan nilai rata-rata 85,00. Sehubungan hasil ini, dapat disimpulkan bahwa metode pembelajaran pronounciation word by word dapat meningkatkan hasil belajar bahasa inggris aspek reading skill ability bagi siswa kelas IV SD Muhammadiyah 2 Parepare.
\end{abstract}

Article History

Received: 17-11-2021

Revised: 09-12-2021

Accepted: 18-12-2021

Published: 07-01-2022

\section{Key Words:}

Pronounciation Word By Word, Reading Skill, Learning Outcomes.

\section{Sejarah Artikel}

Diterima: 17-11-2021

Direvisi: 09-12-2021

Disetujui: 18-12-2021

Diterbitkan: 07-01-2022

\section{Kata Kunci:}

Pronounciation Word By Word, Reading Skill, Hasil Belajar.

How to Cite: Jusran, H. (2022). Upaya Meningkatkan Hasil Belajar Bahasa Inggris Aspek Reading Skill Ability Melalui Pronounciation Word By Word di SD Muhammadiyah 2 Parepare. Jurnal Paedagogy, 9(1), 78-85. doi:https://doi.org/10.33394/jp.v9i1.4462

d.)

https://doi.org/10.33394/jp.v9i1.4462

This is an open-access article under the CC-BY-SA License.

\section{Pendahuluan}

Pendidikan sekolah pada hakikatnya merupakan upaya pembinaan sumber daya manusia Indonesia dalam aspek kognitif, afektif, dan psikomotor (Aswar, 2006). Hal ini ditegaskan dalam Undang-Undang Republik Indonesia Nomor 20 tahun 2003 tentang Sistem Pendidikan Nasional, dimana dalam Pasal 3 berbunyi bahwa fungsi pendidikan nasional yaitu mengembangkan kemampuan dan membentuk watak serta peradaban bangsa yang bermartabat dalam rangka mencerdaskan kehidupan bangsa dan bertujuan untuk berkembangnya potensi peserta didik agar menjadi manusia yang beriman dan bertaqwa kepada Tuhan Yang Maha Esa, berakhlak mulia, sehat, berilmu, cakap, kreatif, mandiri, dan menjadi warga negara yang demokratis serta bertanggung jawab. 
Sekolah dengan berbagai macam teknik dan tenaga pengajar yang memiliki ragam dan variasi teknik dalam mengajar jelas berbeda-beda, terlebih lagi pada jenjang sekolah dasar (Hera, 2005). Sebagaimana di jelaskan dalam Kurikulum Tingkat Satuan Pendidikan bahwa penyelenggarakan pendidikan di sekolah dasar bertujuan: (1) mendidik siswa agar menjadi manusia Indonesia seutuhnya berdasarkan Pancasila yang mampu membangun dirinya sendiri ikut bertanggung jawab terhadap pembangunan bangsa. (2) memberi bekal kemampuan yang diperlukan bagi siswa untuk melanjutkan ke tingkat pendidikan yang lebih tinggi. (3) memberi bekal kemampuan dasar untuk hidup di masyarakat dan mengembangkan diri sesuai bakat, minat, kemampuan, dan lingkungannya (Depdikbud, 1994).

Untuk mewujudkan pembelajaran bermakna diperlukan strategi yang tepat dalam mencapai indikator yang dikehendaki. Strategi adalah pendekatan menyeluruh yang berupa pedoman umum dan kerangka kegiatan untuk mencapai suatu tujuan dan biasanya dijabarkan dari falsafah atau teori tertentu (Peraturan Menteri Nasional Nomor 41 Tahun 2007). Sedangkan menurut Wina Sanjaya (2008) mengatakan bila strategi pembelajaran adalah " $a$ plan of operation achieving something", maka metode yang digunakan adalah " $a$ way in achieving something". Jadi metode pembelajaran dapat diartikan sebagai cara yang digunakan untuk mengimplementasikan susunan rencana dalam bentuk kegiatan nyata dan praktis agar tujuan pembelajaran bisa tercapai.

Chatib (2011) mengisyaratkan bahwa strategi pembelajaran bisa memiliki pengertian sangat luas, mulai dari perencanaan sampai penilaian tiap metode pembelajaran. Dia memberi contoh-contoh implementasi proses pembelajaran dikelas dengan beragam strategi.. saya sangat setuju dengan paparan konsep tersebut, yang intinya strategi pembelajaran memiliki cakupan yang sangat luas untuk diterapkan dalam kegiatan proses pembelajaran.

Bahasa Inggris sangat penting untuk diketahui dan diaplikasikan dalam kehidupan modern saat ini (Komlasari et al., 2020). Bahasa inggris merupakan bahasa asing pertama yang diajarkan ke siswa mulai dari tingkat dasar sampai ke tingkat universitas. Oleh karena itu, seorang guru Bahasa Inggris harus mampu mengaplikasikan pendekatan pembelajaran yang berbeda dalam pengajaran mereka masing-masing (Wahyuningsih, 2021; Muhtasim, 2020). Bahasa Inggris sendiri memiliki empat aspek kebahasaan yang diajarkan, yakni aspek listening (mendengarkan), speaking (berbicara), reading (membaca), dan writing (menulis). Bahasa inggris juga memiliki empat komponen yakni structure (struktur), pronounciation (pengucapan), vocabulary (kosakata), dan grammar (tata bahasa) (Sumaryani, 2015; Nursyamsiah; 2021). Reading (membaca) merupakan salah satu kecakapan berbahasa yang harus dikembangkan, karena dengan banyak membaca banyak informasi kita dapat memperkaya pengetahuan kita. Kecakapan dalam membaca berarti kemampuan untuk memahami, mengerti, dan memaknai pesan yang terkandung di dalam bacaan tersebut.

Pembelajaran Bahasa Inggris khususnya membaca masih merupakan pendekatan pembelajaran yang terpusat pada guru dan telah menjadi kebiasaan dalam waktu yang lama. Siswa hanya diberikan kesempatan untuk mendengarkan apa yang disampaikan oleh guru, mengikuti contoh, mengerjakan soal-soal latihan tanpa terlibat dalam konstruksi pesan yang terkandung dalam bacaan, prinsip, dan analisa terstruktur yang berdasarkan pemikiran siswa itu sendiri. Siswa dalam kegiatan pembelajaran seperti itu, membuatnya menjadi bersikap tertutup. Dan pada khirnya kebiasaan tersebut terus menjadi-jadi sehingga menyebabkan tidak terbiasa bersikap proaktif dalam berinteraksi dengan guru atau teman sebayanya, bahkan bersikap acuh tak acuh terhadap materi yang sedang dipelajarinya. Disamping itu juga, jika hasil belajar siswa rendah, maka akan diasumsikan banyak faktor yang menjadi penyebabnya. Sehinggga nantinya guru tidak serta merta begitu saja mengklaim bahwa 
penyebab utama semata adalah rendahnya kemampuan siswa, hal tersebut bisa saja disebabkan oleh kurangnya pengusaan materi oleh guru atau penggunaan strategi dan bahan ajar yang kurang tepat ataukah kurangnya media pembelajaran yang efektif.

Selain itu, banyak pembelajar Bahasa Inggris yang memiliki masalah dalam belajar kemampuan membaca. Hal ini disebabkan oleh kelemahan dalam mengajarkan kemampuan membaca dan teknik pembelajaran yang diberikan oleh guru tidak sesuai dengan apa yang diharapkan oleh siswa. Pembelajaran Bahasa Ingaris yang seperti itu cenderung membuat siswa merasa bosan dan kurang termotivasi. Hal ini tampak dari siswa berpartisipasi dalam pembelajaran. Hanya kurang 35\% saja siswa yang berpartisipasi aktif. Mereka berpartisipasi hanya pada saat mengerjakan soal latiha-latihan. Selama proses perolehan konsep materi ajar, siswa lebih banyak menyimak dan mendengar informasi dari guru. Tetapi ketika guru memberikan latihan dan materi yang lain, mereka nampak mengalami kesulitan. Mereka seolah-olah asing dengan soal latihan yang diberikan oleh gurunya. Hanya beberapa orang siswa saja yang langsung dapat menyelesaikannya.

Salah satu metode pembelajaran yang mampu meningkatkan kemampuan reading (membaca) siswa dalam pelajaran bahasa inggris adalah metode pembelajaran pronounciation word by word yang mana merupakan konsep belajar yang membantu guru untuk meningkatkan antara materi yang diajarkannya dengan situasi dunia nyata siswa. Dan bisa mendorong siswa membuat hubungan antara pengetahuan yang dimilikinya dengan penerapannya dalam kehidupan mereka sebagai anggota keluarga dan masyarakat. Dengan konsep itu, hasil pembelajaran diharapkan lebih bermakna bagi siswa. Pendekatan ini cocok diterapkan dalam pembelajaran bahasa Inggris. Metode pembelajaran pronounciation word by word ini merupakan tipe dimana siswa dapat bekerja sama, saling membantu, belajar informasi atau keterampilan. Dengan adanya sistem dari peningkatan individu dengan bekerja sama dan berkelompok. Metode pembelajaran pronounciation word by word ini merupakan cara yang efektif untuk mengubah pola belajar dalam kelas. Pembelajaran kooperatif tipe ini memiliki prosedur yang ditetapkan secara eksplisit untuk memberi siswa lebih banyak ruang untuk berpikir, menjawab, dan saling membantu satu sama lain. Adapun penelitian ini bertujuan untuk meningkatkan hasil belajar bahasa inggris aspek reading skill ability melalui metode pembelajaran pronounciation word by word bagi siswa kelas IV SD Muhammadiyah 2 Parepare.

\section{Metode Penelitian}

Metode penelitian ini menggunakan penelitian tindakan kelas (PTK) model Kemmis dan Taggart dalam (Wardani, 2008). Diawali dari aspek mengembangkan perencanaan kemudian melakukan tindakan perencanaan, observasi/pengamatan terhadap tindakan, evaluasi dan diakhiri dengan melakukan refleksi. Penelitian tindakan kelas ini akan dilaksanakan di SD Muhammadiyah 2 Parepare. Dalam Penelitian Tindakan Kelas ini yang menjadi subjek penelitian adalah guru dan siswa kelas IV SD Muhammadiyah 2 Parepare sebanyak 10 siswa yang terdiri dari 5 siswa laki-laki dan 5 siswa perempuan. Memilih siswa kelas IV sebagai subjek disebabkan oleh kurangnya pemahaman yang dialami siswa kelas IV SD Muhammadiyah 2 Parepare pada materi at the school.

Teknik pengumpulan data yang dipergunakan dalam penelitian ini adalah tes, observasi, dan catatan lapangan. Sedangkan teknik analisis data yang digunakan adalah teknik analisis data kualitatif yang dikembangkan oleh Miles dan Huberman (2014) yang terdiri dari tiga tahap kegiatan yaitu: 1) menyelidiki data, 2) menyajikan data, dan 3) menarik kesimpulan dan verifikasi. Untuk mengetahui sejauh mana keberhasilan guru dan siswa 
dalam proses pembelajaran setiap siklusnya, data aspek aktivitas guru dan siswa dalam proses pembelajaran dianalisis berdasarkan kemampuan guru dan siswa melaksanakan indikator yang direncanakan dari setiap tahapan pembelajaran inkuiri. Penafsiran data proses pembelajaran aspek guru dan siswa digunakan acuan dengan rumus:

$$
\frac{\text { Frekuensi }}{\text { Jumlah responden }} \times 100 \%
$$

Indikator keberhasilan dalam penelitian tindakan ini ada dua macam yaitu indikator tentang keterlaksanaan skenario pembelajaran dan indikator kemampuan pemahaman konsep alat indera manusia. Keberhasilan tindakan pada penelitian ini dilihat dari hasil belajar siswa secara keseluruhan pada setiap siklus telah meningkat dan menunjukkan tingkat pencapaian keberhasilan siswa secara keseluruhan mencapai penguasaan $85 \%$ dengan nilai masingmasing setiap subjek penelitian memperoleh nilai paling rendah 75 .

\section{Hasil Penelitian dan Pembahasan \\ Data Siklus I}

Tabel 1. Hasil Tes Akhir Bahasa Inggris Kelas IV SD Muhammadiyah 2 Kota Parepare

\begin{tabular}{|l|l|c|c|c|c|}
\hline No & \multicolumn{1}{|c|}{ Nama Siswa } & L/P & Skor Akhir & Skor Akhir & Penguasaan (\%) \\
\hline 1. & Raedatul aisy & $\mathrm{P}$ & 75 & 7,50 & $75 \%$ \\
\hline 2. & Muhammad Awal & $\mathrm{L}$ & 50 & 5,00 & $50 \%$ \\
\hline 3. & Umriani Umar & $\mathrm{P}$ & 75 & 7,50 & $75 \%$ \\
\hline 4. & Siti Nurqailah & $\mathrm{P}$ & 75 & 7,50 & $75 \%$ \\
\hline 5. & Safwah Nuraqilah & $\mathrm{P}$ & 25 & 2,50 & $25 \%$ \\
\hline 6. & Rina & $\mathrm{P}$ & 50 & 5,00 & $50 \%$ \\
\hline 7. & Muhammad Rifky & $\mathrm{L}$ & 50 & 5,00 & $50 \%$ \\
\hline 8. & Muhammad Rifal & $\mathrm{L}$ & 50 & 5,00 & $50 \%$ \\
\hline 9. & Muhammad & $\mathrm{L}$ & 25 & 2,50 & $25 \%$ \\
\hline Khasim & Ali taqwa & $\mathrm{L}$ & 50 & 5,00 & $50 \%$ \\
\hline JUMLAH & & $\mathbf{5 2 5}$ & $\mathbf{5 2 , 5}$ & $\mathbf{5 2 5} \%$ \\
\hline NILAI RATA-RATA & & 53 & 5,3 & $53 \%$ \\
\hline NILAI DIATAS 75 \% & & 3 & 3 & 3 \\
\hline \multicolumn{2}{|l|}{ NILAI DIBAWAH 75 \% } & & 7 & 7 & $75 \%$ \\
\hline \multicolumn{2}{|l|}{ NILAI TERTINGGI } & & 75 & 7,50 & $25 \%$ \\
\hline \multicolumn{2}{|l}{ NILAI TERENDAH } & & 25 & 2,50 & \\
\hline
\end{tabular}

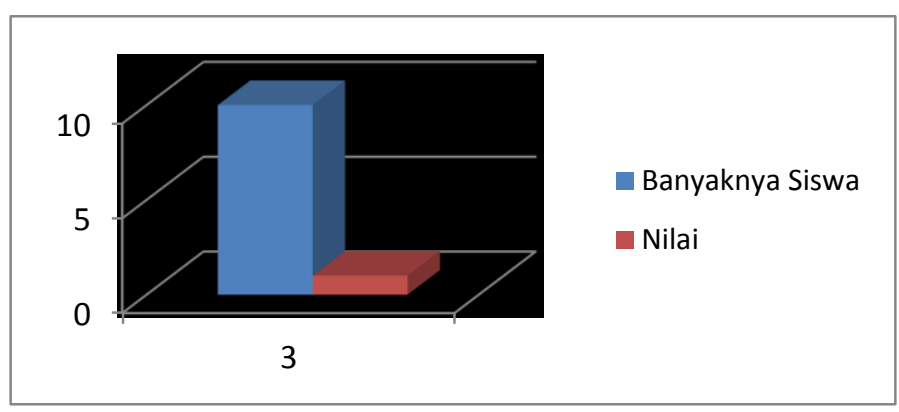

Gambar 1. Grafik Hasil Pengolahan Data Bahasa Inggris Siklus I 


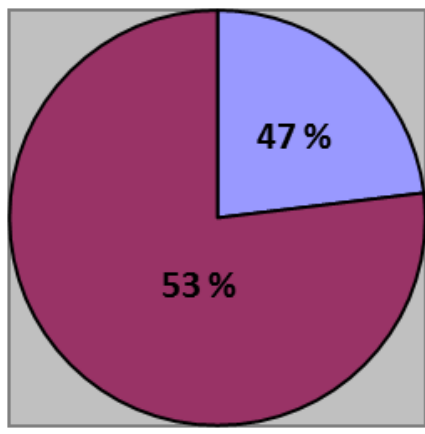

\begin{tabular}{|r|r|r|}
\hline \multicolumn{1}{|c|}{ Nilai } & $\begin{array}{c}\text { Jumlah } \\
\text { Siswa }\end{array}$ & Persentase \\
\hline 10 & 3 & 47 \\
\hline 3 & 7 & 53 \\
\hline total & 10 & 100 \\
\hline
\end{tabular}

\section{Data Siklus II}

Gambar 2. Diagram Hasil Pengolahan Data Bahasa Inggris Siklus I

Tabel 2. Hasil Tes Akhir Bahasa Inggris Kelas IV SD Muhammadiyah 2 Parepare

\begin{tabular}{|l|l|c|c|c|c|}
\hline No & \multicolumn{1}{|c|}{ Nama Siswa } & L/P & Skor Akhir & Skor Akhir & Penguasaan (\%) \\
\hline 1. & Raedatul aisy & P & 100 & 10,00 & $100 \%$ \\
\hline 2. & Muhammad Awal & L & 75 & 7,50 & $75 \%$ \\
\hline 3. & Umriani Umar & P & 100 & 10,00 & $100 \%$ \\
\hline 4. & Siti Nurqailah & P & 100 & 10,00 & $100 \%$ \\
\hline 5. & Safwah Nuraqilah & P & 75 & 7,50 & $75 \%$ \\
\hline 6. & Rina & P & 75 & 8,66 & $75 \%$ \\
\hline 7. & Muhammad Rifky & L & 75 & 8,66 & $75 \%$ \\
\hline 8. & Muhammad Rifal & L & 100 & 9,33 & $100 \%$ \\
\hline 9. & $\begin{array}{l}\text { Muhammad } \\
\text { Khasim }\end{array}$ & L & 75 & 7,50 & $75 \%$ \\
\hline 10. & Ali taqwa & L & 75 & 7,50 & $75 \%$ \\
\hline JUMLAH & & $\mathbf{8 5 0}$ & $\mathbf{8 5 , 0}$ & $\mathbf{8 5 0} \%$ \\
\hline NILAI RATA-RATA & & 85 & 8,5 & $85 \%$ \\
\hline NILAI DIATAS 75 \% & & 10 & 10 & 10 \\
\hline $\begin{array}{l}\text { NILAI DIBAWAH 75 } \\
\%\end{array}$ & & 0 & 0 & 0 \\
\hline \multicolumn{2}{|l|}{ NILAI TERTINGGI } & & 100 & 10,00 & $100 \%$ \\
\hline \multicolumn{2}{l}{ NILAI TERENDAH } & & 75 & 75,00 & $75 \%$ \\
\hline
\end{tabular}

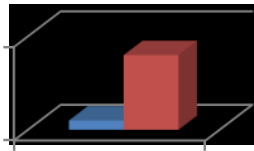

Banyaknya Siswa

- Nilai

10

Gambar 3. Grafik Hasil Pengolahan Data Bahasa Inggris Siklus II 


\begin{tabular}{|r|r|r|}
\hline Nilai & $\begin{array}{c}\text { Jumlah } \\
\text { Siswa }\end{array}$ & Persentase \\
\hline 10 & 7 & 85 \\
\hline 7 & 3 & 15 \\
\hline total & 10 & 100 \\
\hline
\end{tabular}

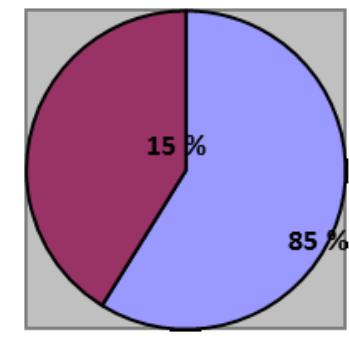

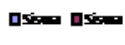

Gambar 4. Diagram Hasil Pengolahan Data Bahasa Inggris Siklus II

Dari data yang diperoleh dengan mengisi lembar observasi selama proses pembelajaran menunjukkan bahwa :

\section{Siklus I}

Berdasarkan hasil pengamatan terhadap pelaksanaan tindakan pada siklus I, didasari bahwa implementasi model pembelajaran dengan pendekatan lingkungan pada proses belajar mengajar belum mencapai tujuan sebagaimana yang diharapkan. Temuan penelitian berdasarkan hasil tindakan siklus I diuraikan sebagai berikut :

1) Siswa belum memahami betul kegunaan prinounciation word by word, pada mata pelajaran Bahasa Inggris kelas IV

2) Siswa secara umum belum menunjukkan partisipasi yang optimal dalam proses pembelajaran.

3) Siswa belum memahami pendekatan lingkungan yang digunakan oleh guru karena siswa terbiasa dengan model pembelajaran secara klasikal namun sebagian siswa telah mampu menyelesaikan soal dengan baik.

\section{Siklus II}

Tindakan untuk siklus II masih menggunakan tahap kegiatan sebagaimana siklus I yakni menggunakan pendekatan lingkungan namun diberikan penekanan untuk perbaikan terhadap kekurangan berdasarkan siklus I. Berdasarkan pengamatan terhadap pelaksanaan tindakan siklus II. Dapat dikatakan bahwa tingkat partisipasi siswa lebih baik dibanding siklus I bahkan sepenuhnya sudah sesuai dengan kriteria keberhasilan penelitian. Hasil refleksi dari siklus II adalah sebagai berikut :

1) Siswa telah menunjukkan keaktifannya dalam belajar dan mulai memahami tentang kegunaan pronounciation word by word pada mata pelajaran Bahasa Inggris kelas IV .

2) Interaksi antara guru dan siswa dalam tanya jawab sudah meningkat dengan baik.

3) Siswa sudah mampu menyelesaikan soal dengan baik.

Tabel 3. Tingkat Pencapaian Hasil Belajar Siswa Per Siklus

\begin{tabular}{|l|c|c|c|c|c|}
\hline \multirow{2}{*}{ MP } & \multirow{2}{*}{ Kelas } & \multicolumn{2}{|c|}{ Siklus I } & \multicolumn{2}{c|}{ Siklus II } \\
\cline { 3 - 6 } & & $\begin{array}{c}\text { Jumlah } \\
\text { siswa }\end{array}$ & $\begin{array}{c}\text { Rata- } \\
\text { rata }\end{array}$ & $\begin{array}{c}\text { Jumla } \\
\text { h siswa }\end{array}$ & Rata-rata \\
\hline A. Ing & IV & 10 & $53 \%$ & 10 & 85 \\
\hline
\end{tabular}


Data siklus I menunjukkan bahwa dari 10 siswa kelas IV, hanya 4 siswa yang berhasil mendapat nilai diatas $75 \%$ dan 6 orang selebihnya mendapatkan perbaikan pembelajaran. Berdasarkan data ini peneliti mengidentifikasi masalah yang menjadi kekurangan dalam pembelajaran, adapun masalah tersebut adalah; (1) Siswa belum memahami betul kegunaan pronounciation word by word, pada mata pelajaran Bahasa Inggris kelas IV; (2) Siswa secara umum belum menunjukkan partisipasi yang optimal dalam proses pembelajaran; dan (3) Siswa belum memahami pendekatan lingkungan yang digunakan oleh guru karena siswa terbiasa dengan model pembelajaran secara klasikal namun sebagian siswa telah mampu menyelesaikan soal dengan baik.

Sedangkan data siklus II menunjukkan bahwa dari 10 siswa kelas IV, 6 siswa telah berhasil mendapatkan nilai diatas 75\%. Dan pada siklus kedua ini pencapaian yang telah diperoleh adalah $100 \%$. Keberhasilan yang telah dicapai adalah sebagai berikut; (1) Siswa telah menunjukkan keaktifannya dalam belajar dan mulai memahami tentang cara pengucakapan setiap kata yang ada di sekolah pada mata pelajaran Bahasa Inggris kelas IV; (2) Interaksi antara guru dan siswa dalam tanya jawab sudah meningkat dengan baik; dan (3) Siswa sudah mampu menyelesaikan soal dengan baik.

\section{Kesimpulan}

Berdasarkan hasil dan analisis data penelitian ini, dapay disimpulkan bahwa peningkatan belajar siswa kelas IV SD Muhammadiyah 2 Parepare melalui Pronounciation word by word adalah pada siklus I masuk dalam kategori rendah dengan jumlah nilai rata-rata 53,00, sedangkan pada siklus II mengalami peningkatan dengan kategori tinggi dengan nilai ratarata 85,00. Sehubungan hasil ini, dapat disimpulkan bahwa metode pembelajaran pronounciation word by word dapat meningkatkan hasil belajar bahasa inggris aspek reading skill ability bagi siswa kelas IV SD Muhammadiyah 2 Parepare.

\section{Saran}

Adapun saran yang disampaikan berdasarkan hasil penelitian ini adalah sebagai berikut:

1) Hendaknya seorang guru mampu menciptakan pembelajaran yang efektif, kreatif dan menyenangkan dalam proses pembelajaran khususnya pada pelajaran Bahasa Inggris melalui pengucapan yang benar agar siswa lebih dekat dengan lingkungan sekitar.

2) Sebaiknya sebelum melakukan pembelajaran guru mendekatkan siswa terlebih dahulu dengan lingkungannya agar siswa dapat lebih mengerti materi pelajaran karena materi pelajaran tersebut sesuai dengan lingkungan siswa.

3) Berdasarkan pengalaman melaksanakan perbaikan pembelajaran melalui PTK kiranya perlu adanya kelompok kerja antara guru untuk selalu bertukar pikiran dan pengalaman yang berkenaan dengan masalah-masalah yang dihadapi dan tugas-tugas mengajar sehari-hari.

\section{Daftar Pustaka}

Aswar. (2006). Dunia Pendidikan. Makassar : Dinas Pendidikan Provinsi Sulawesi Selatan.

Chatib, Munif. (2011). Gurunya Manusia: Menjadikan Semua Anak Istimewa dan Semua Anak Juara. Bandung: Mizan Pustaka

Depdikbud. (1994). Garis-garis Besar Program Pengajar, Jakarta : Departemen Pendidikan dan Kebudayaan.

Hera Lestari Mikarasa. (2005). Pendidikan Anak di SD. Jakarta : Universitas Terbuka. 
Komalasari, R., Rizka, M., \& Tamba, W. (2020). Pola Implementasi Program Kursus Bahasa Inggris Berbasis Masyarakat dalam Meningkatkan Kompetensi Warga Belajar. Jurnal Paedagogy, 7(4), 322-329. doi:https://doi.org/10.33394/jp.v7i4.2860

Miles, M.B, Huberman, A.M. (2014). Qualitative Data Analysis, A Methods Sourcebook, Edition 3. USA: Sage Publications. Terjemahan Tjetjep Rohindi Rohidi, UI-Press

Muhtasim, M. (2020). UPAYA PENERAPAN METODE COOPERATIVE LEARNING TIPE GROUP INVESTIGATION UNTUK MENINGKATKAN HASIL BELAJAR DAN KETERAMPILAN MEMBACA BAHASA INGGRIS SISWA. Jurnal Paedagogy, 2(2), 59-69. doi:https://doi.org/10.33394/jp.v2i2.3049

Mulyani Sumantri. (2004). Perkembangan Peserta Didik, Jakarta : Universitas Terbuka.

Nursyamsiah, E. (2021). Penggunaan Media Aplikasi Duolingo Dalam Meningkatkan Penguasaan Kosakata Bahasa Inggris Siswa Kelas VII SMP Negeri 3 Agrabinta Cianjur. Jurnal Paedagogy, 8(1), 67-77. doi:https://doi.org/10.33394/jp.v8i1.3251

Sanjaya, Wina. (2008). Perencanaan dan desain sistem pembelajaran. Jakarta: Kencana Prenada Media Group.

Suciati. (2005). Belajar dan Pembelajaran 2, Jakarta : Universitas Terbuka.

Sumaryani, L. (2015). Teaching Reading Strategies for Students at FPBS IKIP Mataram. Jurnal Kependidikan: Jurnal Hasil Penelitian dan Kajian Kepustakaan di Bidang Pendidikan, Pengajaran dan Pembelajaran, 1(2). doi:https://doi.org/10.33394/jk.v1i2.419

Wahyuningsih, L. (2021). Meningkatkan Kemampuan Reading Comprehension Siswa SMA Negeri 1 Kebomas Melalui Extensive Reading. Jurnal Paedagogy, 8(1), 112-116. doi:https://doi.org/10.33394/jp.v8i1.3325

Wardhani, IGK. (2008). Penelitian Tindakan Kelas. Jakarta: Universitas Terbuka. 